\title{
Evidence and perspective for the role of the NLRP3 inflammasome signaling pathway in ischemic stroke and its therapeutic potential (Review)
}

\author{
CHONGYANG MA*, SHULING LIU*, SHUANG ZHANG* , TIAN XU, XUE YU, YUSHAN GAO, \\ CHANGMING ZHAI, CHANGXIANG LI, CHAOFANG LEI, SHUNING FAN, YUXI CHEN, \\ HUILING TIAN, QINGGUO WANG, FAFENG CHENG and XUEQIAN WANG
}

School of Basic Medical Sciences, Beijing University of Chinese Medicine, Beijing 100029, P.R. China

Received April 19, 2018; Accepted September 26, 2018

DOI: 10.3892/ijmm.2018.3911

\begin{abstract}
Ischemic stroke is one of the main causes of death and disablement globally. The NLR family pyrin domain containing 3 (NLRP3) inflammasome is established as a sensor of detecting cellular damage and modulating inflammatory responses to injury during the progress of ischemic stroke. Inhibiting or blocking the NLRP3 inflammasome at different stages, including expression, assembly, and secretion, may have great promise to improve the neurological deficits during ischemic stroke. The current review provides a comprehensive summary of the current understanding in the literature of the molecular structure, expression, and assembly of the NLRP3 inflammasome, and highlights its potential as a novel therapeutic target for ischemic stroke.
\end{abstract}

Correspondence to: Dr Xueqian Wang or Dr Fafeng Cheng, School of Basic Medical Sciences, Beijing University of Chinese Medicine, 11 Beisanhuandong Road, Beijing 100029, P.R. China

E-mail: fafengcheng@gmail.com

E-mail: shirlyding@163.com

${ }^{*}$ Contributed equally

Abbreviations: NLRP3, NLR family pyrin domain containing 3; NLRP1, NLR family pyrin domain containing 1; ASC, apoptosis-associated speck-like protein containing CARD; OGD, oxygen-glucose deprivation; ROS, reactive oxygen species; MCAO, middle cerebral artery occlusion; tMCAO, transient MCAO; TJ, tight junction; TXNIP, thioredoxin-interactive protein; BBB, blood brain barrier; GCI, global cerebral ischemia; MAPK, mitogen-activated protein kinase

Key words: NLR family pyrin domain containing 3 inflammasome, ischemic stroke, therapeutic target

\section{Contents}

1. Introduction

2. Overview of NLRP3 inflammasome complex

3. Activation and role of NLRP3 inflammasome in ischemic stroke

4. Expression of the NLRP3 inflammasome complex in the ischemic brain

5. Activation of the NLRP3 inflammasome pathway in ischemic stroke

6. Inhibitors targeting the NLRP3 inflammasome pathway for ischemic stroke treatment

7. Conclusions

\section{Introduction}

Stroke is the third-leading cause of death, following coronary heart disease and cancer, and the main cause of permanent adult disablement in most Western countries (1). In China, it has become the first leading cause of death in recent years (2). Generally, between two main types of stroke, ischemic and hemorrhagic, ischemic stroke accounts for the majority of cases ( 80-90\%) (3-5). Ischemic injury often leads to irreversible cerebral infarction depending on the location, severity, and duration of cerebral blood flow (CBF) reduction, causing cognitive and motor impairment. Based on the pathophysiological characteristics of ischemic stroke, there are currently two major therapeutic strategies: Reperfusion and neuroprotection. Using thrombolytic, antithrombotic and anti-aggregation agents, the blood flow of the compromised region can be restored. However, only one drug, IV Alteplase, is recommended to treat ischemic stroke, and the drug has a very short therapeutic time window and a high risk of hemorrhagic transformation, which severely limits its clinical use (6). The second therapeutic strategy, neuroprotection, aims at preventing neuronal death by regulating multiple intra- or extracellular signals that lead to cell injury. The concept that ischemic penumbra is potentially salvageable is the basis of numerous searches for neuroprotective medications that can save the penumbra tissue and limit the negative consequences 
of stroke (7). However, no drug with proven neuroprotective efficiency and without harmful adverse side effects has been discovered yet. Therefore, it is urgent to develop novel drugs with potential and effective targets.

Inflammation is a defense response aiming at eliminating the primary causes of cell damage. Although inflammation aids in clearing infections and other toxic stimuli, inflammatory responses in the cerebral tissue during an ischemic injury increase the damage for a few hours following the onset of cerebral ischemia (8). During transient or permanent vascular obstruction, all the functions and molecules in the neurons, glial cells (oligodendrocytes, microglia and astrocytes) and vascular cells (endothelial cells and pericytes), identified as components of the neurovascular unit, are affected (9). Dangerous molecular signals are released from the damaged cells following multiple types of cellular stress (10). These signals, including danger signals denominated damage-associated molecular patterns (DAMPs) and pathogen-associated molecular patterns (PAMPs), activate the innate immune system via intracellular and extracellular pattern recognition receptors (PRRs), which have been highlighted recently as an important inflammatory mechanism that may contribute to cerebral ischemic injury (11). Inflammasomes are intracellular protein complexes associated with innate immunity. Activated inflammasomes are able to cleave the precursor of interleukin (IL)-1 $\beta$ and IL-18 to mature forms and initiate a newly discovered programmed inflammatory cell death, pyroptosis, via cleaved caspase-1 (12). In specific, the nucleotide-binding oligomerization domain (NOD)-like receptor (NLR) family pyrin domain containing 3 (NLRP3), which is plentifully expressed in the brain, is regarded as one of the predominant inflammasomes, due to its critical role in recognizing cellular damage and modulating inflammatory responses to ischemia reperfusion injury during ischemic stroke (13). In the current review, we survey the existing evidence for the structure of NLRP3 inflammasome, its activation process in the ischemic brain and the therapeutic potential of blocking or inhibiting NLRP3 inflammasome signaling.

\section{Overview of NLRP3 inflammasome complex}

The inflammasome was first proposed in 2002 as an activator complex of caspase- 1 that generates IL- $1 \beta$ via cleavage of its preform (14). Inflammation is now considered as an important innate immune reaction to multiple types of infection and tissue injury (15). Two kinds of inflammasomes have been established to date: Pyrin and HIN domain-containing protein (PYHIN) inflammasomes and NLR inflammasomes (12). NLRP3 inflammasome is one of the best characterized inflammasomes to date and the most relevant to aseptic inflammation (16). NLRP3, also known as NALP3, is encoded by the cold-induced auto-inflammatory syndrome-1 (CIAS-1) gene and is plentifully expressed in cells of the nervous and immune systems (17). It is commonly comprised of three domains: A C-terminal domain containing leucine-rich repeats (LRRs), a central NACHT domain, and an N-terminal PYD. The LRR domain is implicated in the progress of ligand sensing $(18,19)$. The NACHT domain is responsible for oligomerization and assembly of the central core of the NLRP3 inflammasome, which depends on ATP (20). The
N-terminal PYD domain encourages homotypic PYD/PYD interactions with apoptosis-associated speck-like protein containing CARD (ASC) $(21,22)$, which comprises both PYD and CARD domains and regulates inflammatory response and cell death $(23,24)$. Following danger signals, activation of upstream signals and oligomerization of NLRP3 result in the formation of NLRP3 inflammasome. The NLRP3 inflammasome consists of three cytoplasmic proteins: NLRP3, ASC and the precursor of caspase-1 $(25,26)$. Once binding to NLRP3 via PYD domain, ASC recruits the precursor of caspase-1 via homotypic CARD/CARD interactions (22). Subsequently, activated caspase- 1 is generated, which then cleaves the precursor of proinflammatory cytokines IL-1 $\beta$ and IL-18, and results in the maturation and secretion of these cytokines, inducing cellular pyroptosis (Fig. 1) (27). Recently, multiple studies have reported that excessive activation of NLRP3 inflammasome is closely associated with pathophysiological changes in a majority of inflammatory and non-inflammatory illnesses, including ischemic stroke (28-31).

\section{Activation and role of NLRP3 inflammasome in ischemic stroke}

An increasing number of studies have indicated a key role of NLRP3 inflammasome in recognizing cellular damage and modulating inflammatory responses that eventually result in cell death $(19,32)$. The NLRP3 inflammasome was first associated with ischemic injury in an animal model of renal ischemic injury, which occurs as blockage of blood flow $(33,34)$. Following renal ischemic injury, plenty of evidence proves that activation of NLRP3 is critical in mediating myocardial and liver ischemic damage (35). In the central nervous system (CNS), NLRP3 inflammasome was first reported to be activated in cortical neurons under ischemic conditions and the expression of NLRP3, ASC, caspase-1, IL-1 $\beta$ and IL-18 was upregulated in vitro and in vivo (36). The latter study also demonstrated that suppression of NLRP3 inflammasome activity and neuroprotection resulted from intravenous immunoglobulin (IVIg) and anti-caspase-1 treatment, respectively (36). Another study indicated that deficiency of the NLRP3 gene protected mice from ischemic damage with improved functional outcomes, decreased infarction volume and edema formation, preserved blood brain barrier (BBB) permeability, and reduced inflammatory pathology in a transient middle cerebral artery occlusion (tMCAO) mouse model $(37,38)$, which was first developed in 1986 to mimic ischemic stroke in patients by Koizumi (39). However, several researchers have questioned the role of NLRP3 in the progress of cerebral ischemic injury (40). The conflict between these results could be attributed to differences in ischemic time that may modify the inflammatory response.

After the NLRP3 inflammasome is activated, caspase-1, an evolutionarily conserved enzyme that proteolytically cleaves other proteins, becomes mature. Following ischemic injury in a permanent animal model of stroke, the levels of activated caspase-1 increase at 30 min following surgery, and a second wave of activation comes $12 \mathrm{~h}$ later (41). The upregulated levels of cleaved caspase- 1 have been observed in neurons and astrocytes following cerebral ischemia, and in microglia $24 \mathrm{~h}$ after a stroke (42). Using transgenic mice, the role of caspase-1 has 
been highlighted in the progress of ischemic stroke. Knockout or dominant-negative mutants of caspase-1 inhibited brain damage in contrast to wild type, following experimental stroke $(43,44)$. The therapeutic effects of caspase- 1 molecule inhibitors have also been observed in an oxygen/glucose deprivation model in rat hippocampal slices (45). Collectively, these studies demonstrate a critical role of caspase-1 during ischemic stroke.

Several studies have demonstrated upregulated concentrations of pro-inflammatory factors in the blood, cerebrospinal fluid, and location of blockages of the brain in both clinical patients and experimental animals (46-49), suggesting a localized CNS inflammatory response to ischemic injury. In pathological conditions, premature IL-1 $\beta$ and IL-18 proteins without biological function need to be processed and secreted to exert their pro-inflammatory effects (50). Secreted IL-1 in extracellular space has a direct impact on nearby neurons via IL-1 receptors. High concentrations of IL-1 $\beta$ stimulates phosphorylation and activation of the $\mathrm{N}$-methyl-D-aspartate (NMDA) receptor, which induces excessive calcium flux and excitatory toxicity (51).

\section{Expression of the NLRP3 inflammasome complex in the ischemic brain}

The NLRP3 inflammasome complex, except for immune organs, has also been recently found to be expressed in the brain and spinal cord $(47,50)$. Based on expression data from 11 types of tissues, it was demonstrated that the brain does not express IL-1 $\beta$ and IL-18 constitutively, but expresses NLRP3 inflammasome in a constitutive state, indicating that the NLRP3 inflammasome can be assembled without upregulation of one or two components (52). Expression of the member proteins of the NLRP3 inflammasome complex and IL-1 $\beta$ and IL-18 has been demonstrated to be upregulated in post-mortal brain tissue from stroke patients. A higher level of activated caspase-1 in ischemic brain tissues compared with control brain tissues from patients was further confirmed by immunohistochemical analysis $(36,53)$. At the cellular level, similar to bone marrow-derived macrophages, microglia is the main cell type that expresses NLRP3, ASC and caspase-1 in the brain. However, neither NLRP3 nor ASC can be detected in astrocytes, which highlights the important role of microglia-dependent NLRP3 inflammasome activation under neuroinflammatory conditions (54). In 2014, for the first time, animals subjected to MCAO and cell cultures subjected to oxygen-glucose deprivation (OGD) modeling ischemia/reperfusion injury in vivo and in vitro were used to confirm NLRP3 expression in ischemic stroke. Another study has demonstrated that NLRP3-related proteins are expressed in endotheliocytes and microglia instead of neurons, suggesting that they are the main sources of NLRP3 in the location of the ischemic incident (38). Others found that the levels of NLRP3 inflammasome proteins were also upregulated in primary cortical neurons under ischemic injury (36). Although the specific expression pattern of NLRP3-related proteins in different types of cells in ischemic brain remains unclear, it is certain that NLRP3 inflammasome signaling has an important role in the pathogenesis of ischemic stroke, at the neurovascular unit level. The underlying causes for the differences in the distribution may due to diverse models, ischemic duration and different interventions.

\section{Activation of the NLRP3 inflammasome pathway in ischemic stroke}

The specific intracellular and extracellular signals leading to NLRP3 inflammasome activation are not yet fully understood. Evidence has revealed that assembly of NLRP3 inflammasome and activation of downstream signals depend on two complementary signals associated with cell injury: A priming signal, required for upregulated expression of the NLRP3 inflammasome complex proteins and the precursors of IL-1 $\beta$ and IL-18 through nuclear factor (NF)- $\kappa \mathrm{B}$ and mitogen-activated protein kinase (MAPK) signaling pathways (55); and a second signal that results in NLRP3 activation and ASC phosphorylation, thus triggering their assembly into the NLRP3 inflammasome complex (Fig. 2). In addition, multiple activation mechanisms have been described for the inflammasome, including $\mathrm{K}^{+}$ efflux, reactive oxygen species (ROS) overproduction, mitochondrial dysfunction, $\mathrm{Ca}^{2+}$ overload, and lysosome rupture. Notably, these mechanisms also overlap with the two-step activation of the NLRP3 inflammasome. It is well-established that these mechanisms exist in the progress of ischemic stroke. Several experts have confirmed that reducing the ATP/ADP ratio following ischemic stroke opens the channel and allows $\mathrm{K}^{+}$ions to exit the cells via potassium channels (56). Mitochondrial dysfunction (57), ROS overproduction (58) and $\mathrm{Ca}^{2+}$ overload (59) are also known to have important roles in the amplification and transmission of ischemic injury.

NLRP3, pro-IL-1 $\beta$ and pro-IL-18 do not abound in physiological conditions, and therefore a priming signal, specifically the upregulation of NLRP3-related proteins, is necessary for the activation of NLRP3 inflammasome. In addition, several plasma membrane pattern recognition receptors (PRRs), such as toll-like receptors (TLRs) and receptor for advanced glycation end-products (RAGE), and downstream adaptor proteins, such as myeloid differentiation primary response gene 88 (MyD88) and tumor necrosis factor receptor-associated factor 6 (TRAF6), may serve a role in activation of two phosphorylation signaling pathways, NF- $\kappa$ B and MAPK (60-63). Both of the latter signaling pathways are considered to regulate both the expression of the member proteins of the NLRP3 inflammasome complex, and the expression of the precursors of IL-1 $\beta$ and IL-18 during the inflammatory response to specific cellular stress (64-66).

As aforementioned, after the activating priming signal, ASC, an adaptor protein, recruits NLRP3 proteins and forms the NLRP3 inflammasome complex. Of all the intracellular and extracellular factors, the best-studied stimulus, $\mathrm{K}^{+}$efflux, has been demonstrated to have a role in activation of the NLRP3 inflammasome (67). This non-selective $\mathrm{K}^{+}$cation channel on the cell surface is able to change intracellular ionic contents depending on ATP binding and to activate downstream signals, inducing maturation and secretion of IL-1 $\beta$ (68). Previous studies have demonstrated that downregulated levels of intracellular $\mathrm{K}^{+}$are indispensable for activation of the NLRP3 inflammasome pathway when compared with other known stimuli, which highlighted the role of $\mathrm{K}^{+}$efflux in this process. $\mathrm{P} 2 \mathrm{X}$ purinoceptor $7(\mathrm{P} 2 \mathrm{X} 7 \mathrm{R})$ is one of the 


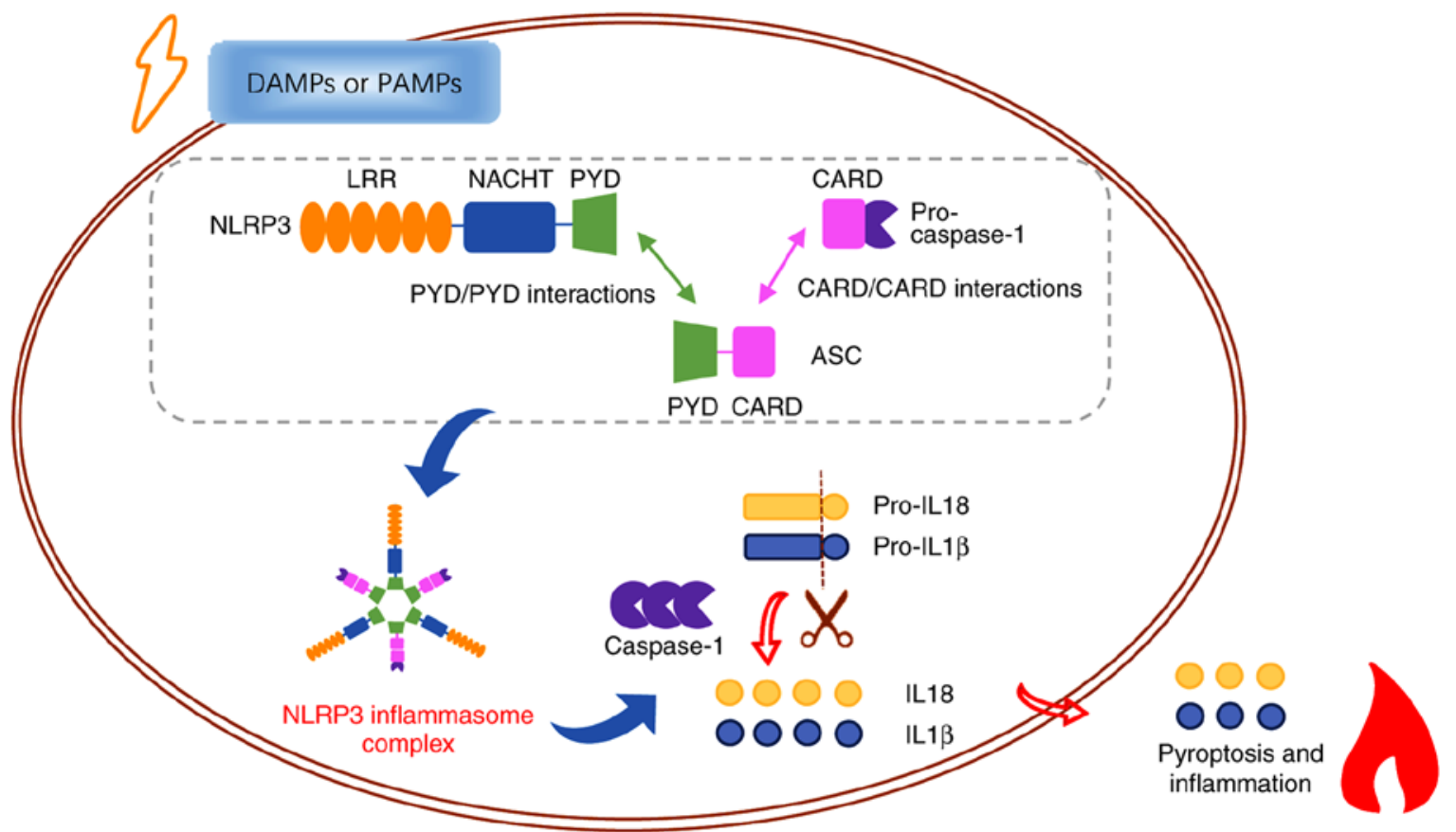

Figure 1. Structure of the NLRP3 inflammasome complex. The NLRP3 inflammasome complex consists of NLRP3, ASC and pro-caspase1. NLRP3 is composed of three domains: A C-terminal domain containing LRRs, a central NACHT domain, and an N-terminal PYD. The ASC protein is composed of a PYD and a CARD. Following DAMPs or PAMPs activating upstream signaling pathways, homotypic interactions between homotypic domains, such as NATCH/NATCH, PYD/PYD and CARD/CARD, have a key role in assembly of the NLRP3 inflammasome. Finally, pro-caspase1 is cleaved to form the bioactive caspase1, which then induces the maturation and secretion of IL-1 $\beta$ and IL-18, and subsequently pyroptosis. NLRP3, NLR family pyrin domain containing 3; ASC, apoptosis-associated speck-like protein containing CARD; LRRs, leucine-rich repeats; PYD, pyrin domain; CARD, caspase recruitment domain; DAMPs, danger associated molecular patterns; PAMPs, pathogen-associated molecular patterns; IL, interleukin.

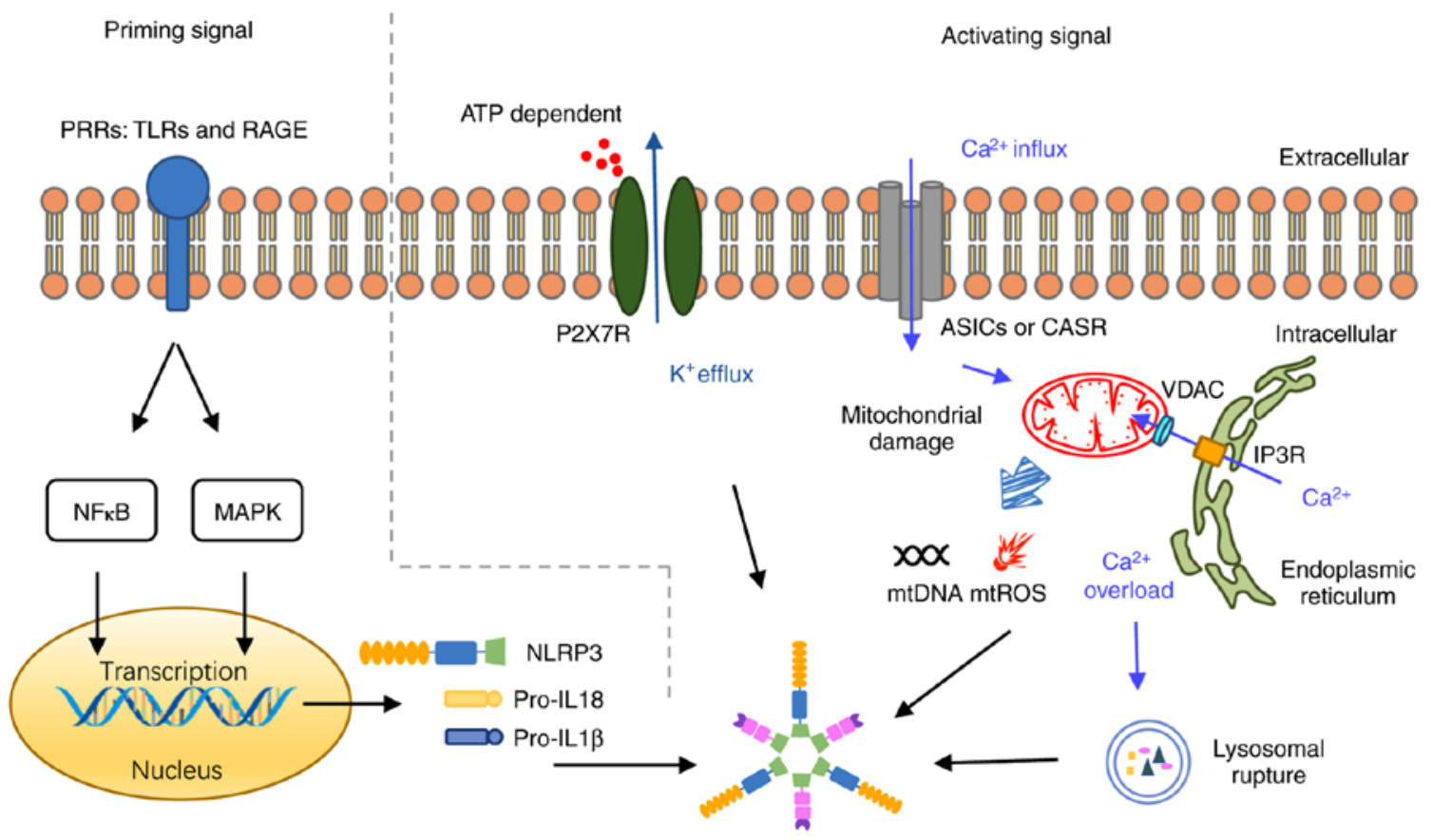

NLRP3 inflammasome

Figure 2. Activation of the NLRP3 inflammasome signaling pathway in ischemic stroke. Two steps of activation have been recognized: The priming and the activating. For the priming step, PRRs, such as TLRs and RAGE, are major initiative signals that upregulate the expression of the NLRP3 inflammasome complex proteins and of pro-inflammatory cytokines, via transcription factors such as NF- $\kappa$ B and MAPK. Following the priming step, ASC, an adaptor protein, recruits NLRP3 and forms the NLRP3 inflammasome complex. Finally, intracellular and extracellular stimuli, including disruption of $\mathrm{K}^{+}$ and $\mathrm{Ca}^{2+}$ homeostasis, and mtDNA and mtROS release from mitochondrial dysfunction and lysosomal rupture, have been demonstrated to have important roles in activation of the NLRP3 inflammasome. NLRP3, NLR family pyrin domain containing 3; PRRs, plasma membrane pattern recognition receptors;

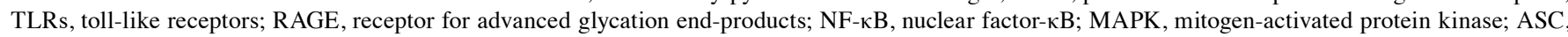
apoptosis-associated speck-like protein containing CARD; mt, mitochondrial; ROS, reactive oxygen species; IL, interleukin; P2X7R, P2X purinoceptor 7; ASICs, acid-sensing ion channels; CASR, calcium-sensing receptor; VDAC, voltage-dependent anion channels; IP3R, inositol 1,4,5-trisphosphate receptor. 
best-characterized receptors associated with $\mathrm{K}^{+}$efflux, whose activation might induce release of pro-inflammatory cytokines and amplify ischemic injury via ATP. Experimental evidence from P2X7R knockdown mice confirmed the role of this receptor in NLRP3 inflammasome response (69).

Mitochondrial damage is another important activation mechanism of the NLRP3 inflammasome. The mitochondrion is a double-membrane-bound intracellular organelle and the predominant location in the cell that produces both energy and reactive oxygen species (ROS) (70). Previous research has indicated that high levels of ROS under multiple kinds of cellular stress, particularly those produced by mitochondria (mtROS), activates the NLRP3 inflammasome signal pathway (71-74). In detail, high levels of ROS induce the ROS scavenging protein thioredoxin resolving from thioredoxin interacting/inhibiting protein (TXNIP), which then directly binds with NLRP3 proteins and modulates its assembly via oligomerization (75-77). Although several investigations have demonstrated that TXNIP is necessary for NLRP3 inflammasome assembly, a cell type-specific modulation of TXNIP occurs, which limits its mediation of inflammatory response ROS signaling pathway activation to particular cell types (78-80). In addition to mtROS, dysfunctional mitochondria also release mitochondrial DNA (mtDNA) into the cytoplasm, directly inducing the assembly of NLRP3 inflammasome complex via molecular self-association (81-83). Of note, appropriate amount of nitric oxide, another kind of free radical, is able to trigger a cascade to modulate mitochondrial permeability, limit mtROS releases and suppress NLRP3 inflammasome activation $(84,85)$.

Previous evidence has demonstrated that intracellular level of $\mathrm{Ca}^{2+}$ is associated with the activation of NLRP3 inflammasome, which highlights the role of calcium homeostasis in NLRP3 inflammasome signaling. An early study reported that increased levels of intracellular $\mathrm{Ca}^{2+}$ along with decreased levels of $\mathrm{K}^{+}$activate the NLRP3 inflammasome pathway and release mature IL-1 $\beta$ and IL-18 via P2X7R, as aforementioned (86). Later, it was demonstrated that both suppression of extracellular $\mathrm{Ca}^{2+}$ influx via membrane receptor and inhibition of intracellular $\mathrm{Ca}^{2+}$ overload depending on endoplasmic reticulum (ER) were able to block NLRP3 inflammasome activation and IL-1 $\beta$ maturation and secretion by ATP, nigericin, and alum (87), indicating a key role of $\mathrm{Ca}^{2+}$ level in NLRP3 inflammasome activation (88). Notably, via $\mathrm{Ca}^{2+}$ overload, mitochondrial damage and ER stress are among the best-described pathological factors activating the NLRP3 inflammasome pathway. Extracellular $\mathrm{Ca}^{2+}$ may enter the cell trough plasma membrane-resident $\mathrm{Ca}^{2+}$ channels called acid-sensing ion channels (ASICs) $(89,90)$. The calcium-sensing receptor (CASR) has also been reported to increase the concentration of intracellular $\mathrm{Ca}^{2+}$, initiate the phospholipase $\mathrm{C}$ pathway via the intracellular side and induce assembly of the NLRP3 inflammasome complex (91). Mitochondria-associated membranes (MAM), a mechanism resulting from crosstalk between ER and mitochondria, are involved in $\mathrm{Ca}^{2+}$ flux from ER to mitochondria via inositol 1,4,5-trisphosphate receptor (IP3R) and mitochondrial voltage-dependent anion channels (VDAC) $(92,93)$. Pathologically high levels of $\mathrm{Ca}^{2+}$ can induce NLRP3 inflammasome activation via two different mechanisms: By enhancing mtROS production, with associated mitochondrial destabilization (94); and by inducing lysosomal rupture, resulting in lysosome contents being released into the cytosol, particularly cathepsin B, which binds to the LRR domain of NLRP3 and triggers NLRP3 signaling $(95,96)$. Cathepsin $\mathrm{B}$ is also activated by the TAK1 kinase and is involved in the activation of MAPKs, one of which participates in the priming step to activate the NLRP3 inflammasome (97-99).

\section{Inhibitors targeting the NLRP3 inflammasome pathway for ischemic stroke treatment}

Accumulating evidence indicates that the NLRP3 inflammasome has an important role in ischemic brain injury. Targeting upstream or downstream of the NLRP3 inflammasome pathway at the molecular level, including modulating protein expression, assembly, activation and/or secretion, may have a promising prospect in developing novel therapeutic agents for ischemic stroke (Table I). Core proteins involved in the NF- $\kappa \mathrm{B}$ and MAPK pathways, proteins of the NLRP3 inflammasome complex, plasma membrane receptors or channels, cytokines (IL-1 $\beta$ and IL-18) and their receptors may serve as potential therapeutic targets for ischemic stroke (19). A previous study focused on the effect of Bay-11-7082 (an NF- $\kappa$ B inhibitor), SB 203580 (a P38-MAPK inhibitor), JNK Inhibitor V (a JNK inhibitor), and U-0126 (an ERK inhibitor) on a mice tMCAO model and in neurons undergoing OGD, and demonstrated that all of these inhibitors protected neurons during simulated ischemia, via attenuating the levels of NLRP3 inflammasome complex, and via inhibiting activation of NLRP3 inflammasome and maturation of IL-1 $\beta$ and IL-18 (100). Probenecid, a pannexin 1 inhibitor, has also been found to induce astrocyte death and ROS generation, attenuate expression levels of NLRP3 and inhibit the extracellular release of IL-1 $\beta$ (101). MCC950 and glyburide, both NLRP3 oligomerization inhibitors, reduce infarction volume, neuronal apoptosis, and neurological impairment, and have anti-oxidative stress and anti-inflammatory effects, respectively (102-105). Recently, several natural compounds, including resveratrol, paeoniflorin and sinomenine, were also demonstrated to reduce cerebral infarction volume, decrease brain water content, improve neurological scores and grip strength, and prevent neuronal cell death following ischemic stroke, through downregulating the expression of the components of the NLRP3 inflammasome and their downstream proteins and attenuating its activation (106-108). However, there is little clinical data on the effects of these agents to date. Further studies are required to examine the efficiency and safety of these agents in the clinic in the future.

Although targeting the NLRP3 inflammasome pathway rather than anti-ischemic systems may develop promising therapeutic strategies to treat ischemic stroke, several aspects of this potential treatment must be clarified. Firstly, the specific expression pattern of NLRP3 activation in specific cell types and brain regions following ischemic injury require further investigation. Additionally, whether the upstream pathways are different among various cell types remains to be elucidated. Secondly, it is well known that whether inflammation will have destructive or beneficial effects depends on the severity, frequency, and duration of ischemic injury. It is 
MA et al: NLRP3 INFLAMMASOME IN ISCHEMIC STROKE

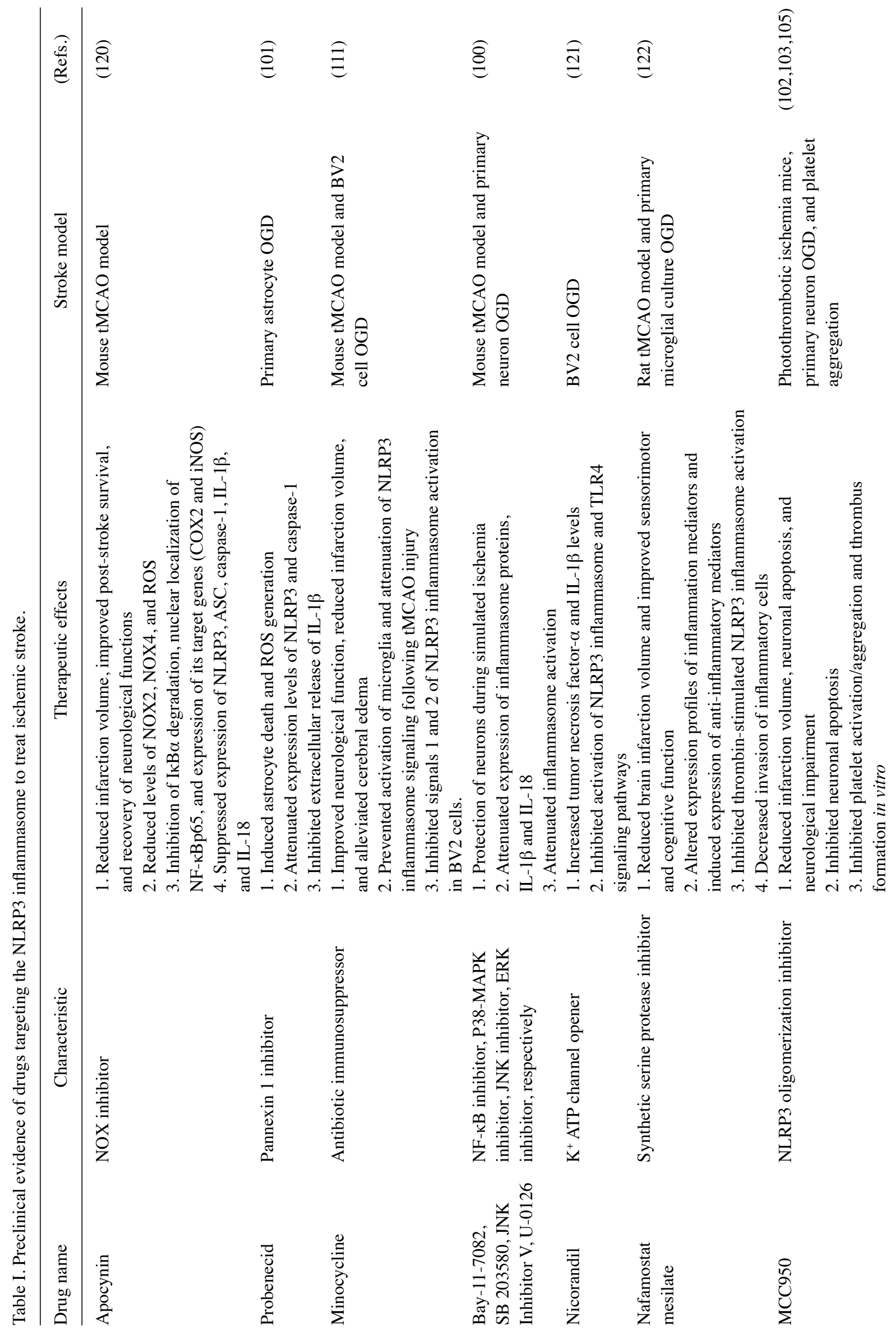




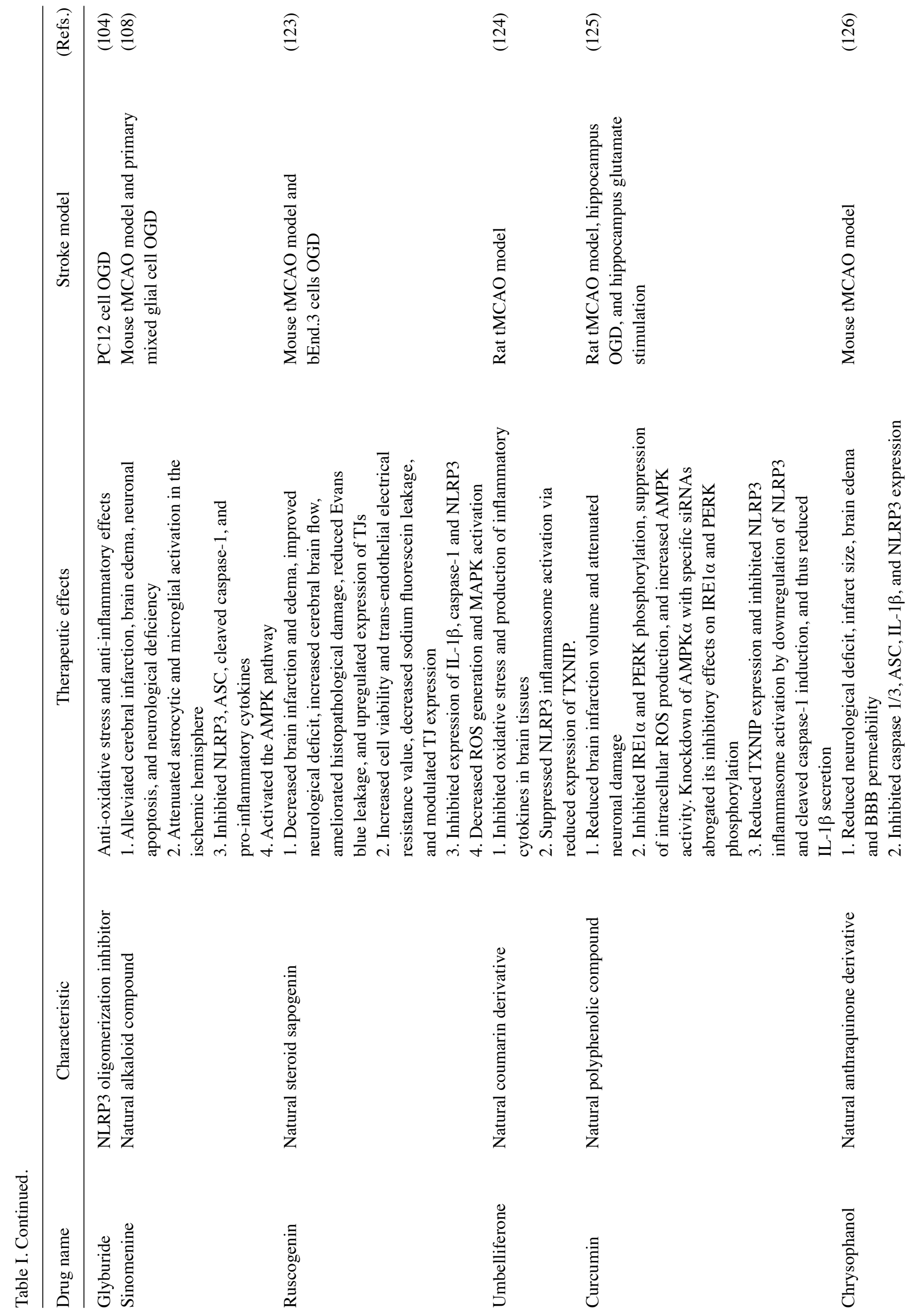




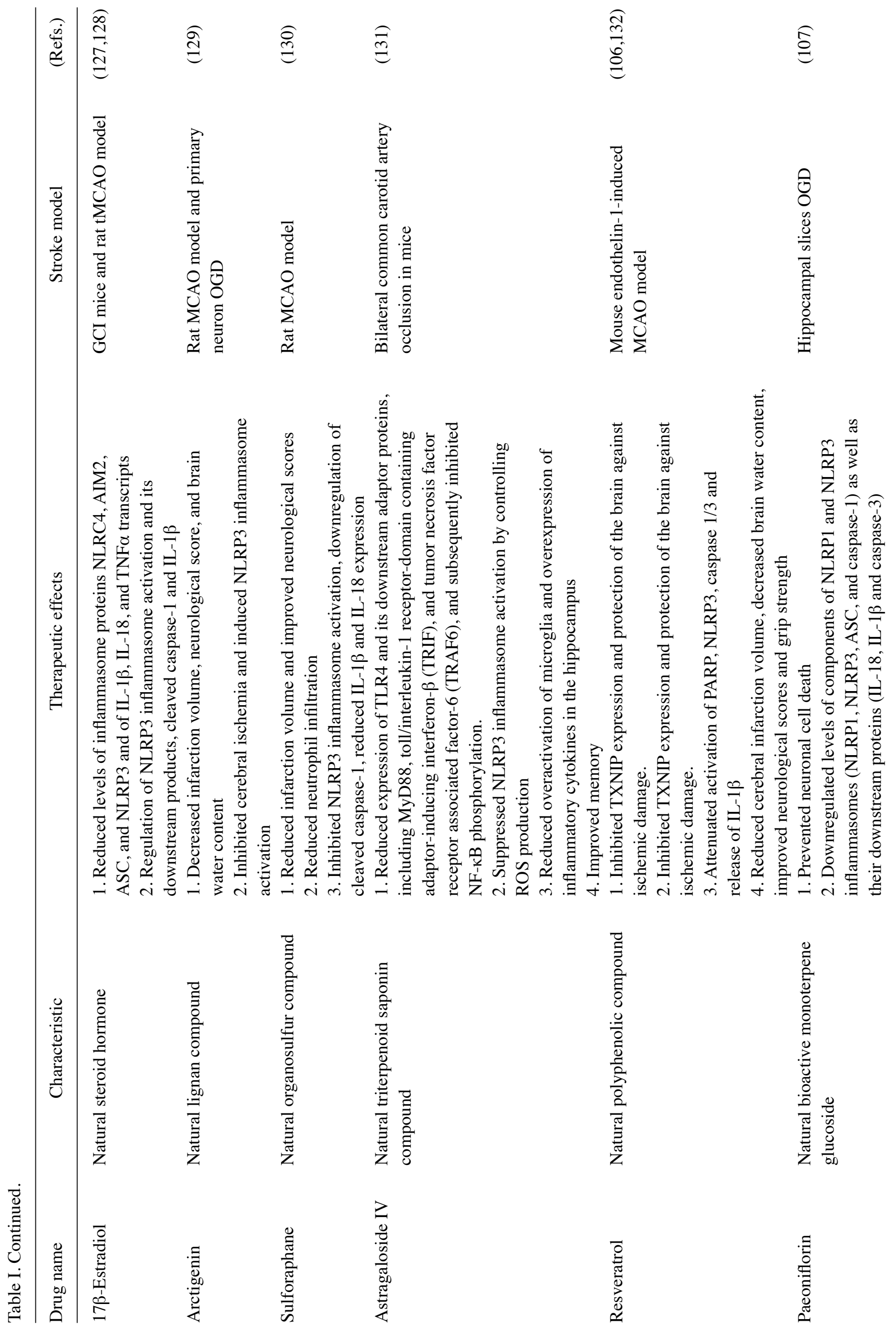


possible that early immune responses may aggravate ischemic injury, while late responses may help to repair the damaged region. Therefore, early inhibition of the NLRP3 inflammasome pathway may be a beneficial and reasonable choice. On the other hand, using animal models, some anti-neuroinflammation agents have been demonstrated to protect ipsilateral brain against ischemic injury up to 7 days following ischemic induction (109-111), which highlights the long-term effect and application prospect of immunotherapy. Of note, intermittent fasting has been reported to attenuate NLRP3 pathway activity and repair damaged tissues up to 4 months following ischemic stroke (112). Future studies should focus on the optimal timing of NLRP3 inhibitor administration and explain the mechanisms behind damaging and protective actions of the immune system in ischemic stroke.

Finally, after glyburide was first found to selectively inhibit activation of the NLRP3 inflammasome without interfering with other inflammasome pathways (113), two other selective and direct NLRP3 inhibitors, CY-09 (114) and CP-456,773 (115,116), were recently identified. These drugs might provide a novel avenue toward therapeutic inhibition of the NLRP3 inflammasome, although their effect in ischemic stroke remains to be determined. Many NLRP3 inhibitors found to have benefits following ischemic stroke were identified as natural compounds, and further research should elucidate the relationship between molecular structure and anti-NLRP3 inflammasome function. Furthermore, several microRNAs have been demonstrated to influence the NLRP3 inflammasome pathway, including miR-22 (117), miR-132 (118), and long non-coding RNA XLOC_000647 (119). Further studies should consider the modulation of the NLRP3 inflammasome post-stroke via epigenetic approaches.

\section{Conclusions}

In conclusion, illuminating the role of NLRP3 inflammasome signaling pathways in ischemic injury will provide significant knowledge and opportunities to clarify the relationship between the innate immune system and the nervous system in the pathophysiology of ischemic stroke. Above all, more and larger clinical studies examining the associations between clinical symptoms and signs and the expression levels of NLRP3 inflammasome network proteins in brain parenchyma and body fluids are urgently needed. Research to identify and design compounds and therapeutic strategies to target the NLRP3 inflammasome and modulate the detrimental inflammatory processes without excessively disturbing the immune defense progress may be essential for the treatment of ischemic stroke. Extensive clinical trials are required to develop safer and more effective agents targeting the NLRP3 inflammasome pathway in humans.

\section{Acknowledgements}

Not applicable.

\section{Funding}

This review was supported by the National Natural Science Foundation of China (grant nos. 81430102, 81774122,
81774030, 81373886 and 81303260) and the Beijing University of Traditional Chinese Medicine Independent Subject Selection Project (grant no. 2017-JYB-XS-014).

\section{Availability of data and materials}

Not applicable.

\section{Authors' contributions}

FC, XW, CM, SL, SZ, TX made substantial contributions to the conception of the present study and wrote the manuscript and critically reviewed it. XY, YG, CZ, CLe, CLi, SF, HT, YC, $\mathrm{QW}$ contributed to searching related articles and reviewing the article. All authors read and approved the final manuscript.

\section{Ethics approval and consent to participate}

Not applicable.

\section{Patient consent for publication}

Not applicable.

\section{Competing interests}

The authors declare that they have no competing interests.

\section{References}

1. Feigin VL, Krishnamurthi RV, Parmar P, Norrving B, Mensah GA, Bennett DA, Barker-Collo S, Moran AE, Sacco RL, Truelsen T, et al: Update on the global burden of ischemic and hemorrhagic stroke in 1990-2013: The GBD 2013 study. Neuroepidemiology 45: 161-176, 2015.

2. Wang W, Jiang B, Sun H, Ru X, Sun D, Wang L, Jiang Y, Li Y, Wang Y, Chen Z, et al: Prevalence, incidence, and mortality of stroke in chinaclinical perspective: Results from a nationwide population-based survey of 480687 adults. Circulation 135: 759-771, 2017.

3. Liu L, Wang D, Wong KL and Wang Y: Stroke and stroke care in china: Huge burden, significant workload, and a national priority. Stroke 42: 3651-3654, 2011.

4. Benjamin EJ, Blaha MJ, Chiuve SE, Cushman M, Das SR, Deo R, de Ferranti SD, Floyd J, Fornage M, Gillespie C, et al: Heart disease and stroke statistics-2017 update: A report from the american heart association. Circulation 135: e146-e603, 2017.

5. Goldstein LB, Adams R, Alberts MJ, Appel LJ, Brass LM, Bushnell CD, Culebras A, Degraba TJ, Gorelick PB, Guyton JR, et al: Primary prevention of ischemic stroke: A guideline from the american heart association/american stroke association stroke council: Cosponsored by the atherosclerotic peripheral vascular disease interdisciplinary working group; cardiovascular nursing council; clinical cardiology council; nutrition, physical activity, and metabolism council; and the quality of care and outcomes research interdisciplinary working group: The american academy of neurology affirms the value of this guideline. Stroke 37: 1583-1633, 2006

6. Furie KL and Jayaraman MV: 2018 guidelines for the early management of patients with acute ischemic stroke. Stroke 49: 509-510, 2018.

7. Astrup J, Siesjö BK and Symon L: Thresholds in cerebral ischemia-the ischemic penumbra. Stroke 12: 723-725, 1981.

8. Hu X, De Silva TM, Chen J and Faraci FM: Cerebral vascular disease and neurovascular injury in ischemic stroke. Circ Res 120: 449-471, 2017.

9. Famakin BM: The immune response to acute focal cerebral ischemia and associated post-stroke immunodepression: A focused review. Aging Dis 5: 307-326, 2014. 
10. Cai W, Zhang K, Li P, Zhu L, Xu J, Yang B, Hu X, Lu Z and Chen J: Dysfunction of the neurovascular unit in ischemic stroke and neurodegenerative diseases: An aging effect. Ageing Res Rev 34: 77-87, 2017.

11. Cuartero MI, Ballesteros I, Lizasoain I and Moro MA: Complexity of the cell-cell interactions in the innate immune response after cerebral ischemia. Brain Res 1623: 53-62, 2015.

12. Hoseini Z, Sepahvand F, Rashidi B, Sahebkar A, Masoudifar A and Mirzaei H: NLRP3 inflammasome: Its regulation and involvement in atherosclerosis. J Cell Physiol 233: 2116-2132, 2018.

13. Elliott EI and Sutterwala FS: Initiation and perpetuation of NLRP3 inflammasome activation and assembly. Immunol Rev 265: 35-52, 2015

14. Martinon F, Burns K and Tschopp J: The inflammasome: A molecular platform triggering activation of inflammatory caspases and processing of proIL-beta. Mol Cell 10: 417-426, 2002.

15. Medzhitov R: Origin and physiological roles of inflammation. Nature 454: 428-435, 2008.

16. Cassel SL and Sutterwala FS: Sterile inflammatory responses mediated by the NLRP3 inflammasome. Eur J Immunol 40: 607-611, 2010.

17. Liu SB, Mi WL and Wang YQ: Research progress on the NLRP3 inflammasome and its role in the central nervous system. Neurosci Bull 29: 779-787, 2013.

18. Liao KC and Mogridge J: Expression of Nlrplb inflammasome components in human fibroblasts confers susceptibility to anthrax lethal toxin. Infect Immun 77: 4455-4462, 2009.

19. Fann DY, Lee SY, Manzanero S, Chunduri P, Sobey CG and Arumugam TV: Pathogenesis of acute stroke and the role of inflammasomes. Ageing Res Rev 12: 941-966, 2013.

20. Levinsohn JL, Newman ZL, Hellmich KA, Fattah R, Getz MA Liu S, Sastalla I, Leppla SH and Moayeri M: Anthrax lethal factor cleavage of Nlrp1 is required for activation of the inflammasome. PLoS Pathog 8: e1002638, 2012.

21. Gambin Y, Giles N, O'Carroll A, Polinkovsky ME, Hunter DJ and Sierecki E: Single-molecule fluorescence reveals the oligomerisation and folding steps driving the prion-like behaviour of ASC. J Mol Biol 430: 1263, 2018.

22. Srinivasula SM, Poyet JL, Razmara M, Datta P, Zhang Z and Alnemri ES: The PYRIN-CARD protein ASC is an activating adaptor for caspase-1. J Biol Chem 277: 21119-21122, 2002.

23. Shi J, Gao W and Shao F: Pyroptosis: Gasdermin-mediated programmed necrotic cell death. Trends Biochem Sci 42 245-254, 2017.

24. Inohara $\mathrm{N}$ and Nuñez G: Cell death and immunity: NODs: Intracellular proteins involved in inflammation and apoptosis Nat Rev Immunol 3: 371-382, 2003.

25. Agostini L, Martinon F, Burns K, McDermott MF, Hawkins PN and Tschopp J: NALP3 forms an IL-1beta-processing inflammasome with increased activity in Muckle-Wells autoinflammatory disorder. Immunity 20: 319-325, 2004

26. Schroder K and Tschopp J: The inflammasomes. Cell 140 821-832, 2010

27. Kanneganti TD: Inflammatory bowel disease and the NLRP3 inflammasome. N Engl J Med 377: 694-696, 2017.

28. Ozaki E, Campbell M and Doyle SL: Targeting the NLRP3 inflammasome in chronic inflammatory diseases: Current perspectives. J Inflamm Res 8: 15-27, 2015.

29. Alcocer-Gómez E, Castejón-Vega B and Cordero MD: Stress-induced NLRP3 inflammasome in human diseases. Adv Protein Chem Struct Biol 108: 127-162, 2017.

30. Song L, Pei L, Yao S, Wu Y and Shang Y: NLRP3 inflammasome in neurological diseases, from functions to therapies. Front Cell Neurosci 11: 63, 2017.

31. Toldo S and Abbate A: The NLRP3 inflammasome in acute myocardial infarction. Nat Rev Cardiol 15: 203-214, 2018.

32. Pradillo JM, Denes A, Greenhalgh AD, Boutin H, Drake C, McColl BW, Barton E, Proctor SD, Russell JC, Rothwell NJ, et al: Delayed administration of interleukin-1 receptor antagonist reduces ischemic brain damage and inflammation in comorbid rats. J Cereb Blood Flow Metab 32: 1810-1819, 2012.

33. Iyer SS, Pulskens WP, Sadler JJ, Butter LM, Teske GJ, Ulland TK, Eisenbarth SC, Florquin S, Flavell RA, Leemans JC and Sutterwala FS: Necrotic cells trigger a sterile inflammatory response through the Nlrp3 inflammasome. Proc Natl Acad Sci USA 106: 20388-20393, 2009.

34. Shigeoka AA, Mueller JL, Kambo A, Mathison JC, King AJ, Hall WF, Correia Jda S, Ulevitch RJ, Hoffman HM and McKay DB: An inflammasome-independent role for epithelial-expressed Nlrp3 in renal ischemia-reperfusion injury. J Immunol 185: 6277-6285, 2010.
35. Leemans JC, Cassel SL and Sutterwala FS: Sensing damage by the NLRP3 inflammasome. Immunol Rev 243: 152-162, 2011

36. Fann DY, Lee SY, Manzanero S, Tang SC, Gelderblom M, Chunduri P, Bernreuther C, Glatzel M, Cheng YL, Thundyil J, et al: Intravenous immunoglobulin suppresses NLRP1 and NLRP3 inflammasome-mediated neuronal death in ischemic stroke. Cell Death Dis 4: e790, 2013.

37. Dong Y, Fan C, Hu W, Jiang S, Ma Z, Yan X, Deng C, Di S, Xin Z, Wu G, et al: Melatonin attenuated early brain injury induced by subarachnoid hemorrhage via regulating NLRP3 inflammasome and apoptosis signaling. J Pineal Res 60: 253-262, 2016

38. Yang F, Wang Z, Wei X, Han H, Meng X, Zhang Y, Shi W, Li F, Xin T, Pang Q, et al: NLRP3 deficiency ameliorates neurovascular damage in experimental ischemic stroke. J Cereb Blood Flow Metab 34: 660-667, 2014.

39. Koizumi J: Experimental studies of ischemic brain edema. 1. A new experimental model of cerebral embolism in rats in which recirculation can be introduced in the ischemic area. Jpn J Stroke 8: 1-8, 1986.

40. Denes A, Coutts G, Lénárt N, Cruickshank SM, Pelegrin P, Skinner J, Rothwell N, Allan SM and Brough D: AIM2 and NLRC4 inflammasomes contribute with ASC to acute brain injury independently of NLRP3. Proc Natl Acad Sci USA 112: 4050-4055, 2015

41. Benchoua A, Guégan C, Couriaud C, Hosseini H, Sampaïo N, Morin D and Onténiente B: Specific caspase pathways are activated in the two stages of cerebral infarction. J Neurosci 21: 7127-7134, 2001.

42. Abulafia DP, de Rivero Vaccari JP, Lozano JD, Lotocki G, Keane RW and Dietrich WD: Inhibition of the inflammasome complex reduces the inflammatory response after thromboembolic stroke in mice. J Cereb Blood Flow Metab 29: 534-544, 2009.

43. Friedlander RM, Gagliardini V, Hara H, Fink KB, Li W, MacDonald G, Fishman MC, Greenberg AH, Moskowitz MA and Yuan J: Expression of a dominant negative mutant of interleukin-1beta converting enzyme in transgenic mice prevents neuronal cell death induced by trophic factor withdrawal and ischemic brain injury. J Exp Med 185: 933-940, 1997.

44. Schielke GP, Yang GY, Shivers BD and Betz AL: Reduced ischemic brain injury in interleukin-1beta converting enzymedeficient mice. J Cereb Blood Flow Metab 18: 180-185, 1998.

45. Ray AM, Owen DE, Evans ML, Davis JB and Benham CD: Caspase inhibitors are functionally neuroprotective against oxygen glucose deprivation induced CA1 death in rat organotypic hippocampal slices. Brain Res 867: 62-69, 2000.

46. Mathiesen T, Edner G, Ulfarsson E and Andersson B: Cerebrospinal fluid interleukin-1 receptor antagonist and tumor necrosis factor- $\alpha$ following subarachnoid hemorrhage. J Neurosurg 87: 215-220, 1997.

47. Iadecola $\mathrm{C}$ and Anrather J: The immunology of stroke: From mechanisms to translation. Nat Med 17: 796-808, 2011.

48. Mathiesen T, Andersson B, Loftenius A and von Holst H: Increased interleukin-6 levels in cerebrospinal fluid following subarachnoid hemorrhage. J Neurosurg 78: 562-567, 1993.

49. Mizuma A and Yenari MA: Anti-inflammatory targets for the treatment of reperfusion injury in stroke. Front Neurol 8: 467, 2017.

50. Creagh EM: Caspase crosstalk: Integration of apoptotic and innate immune signalling pathways. Trends Immunol 35: 631-640, 2014.

51. Galea J and Brough D: The role of inflammation and interleukin-1 in acute cerebrovascular disease. J Inflamm Res 6: 121-128, 2013.

52. Yin Y, Yan Y, Jiang X, Mai J, Chen NC, Wang H and Yang XF: Inflammasomes are differentially expressed in cardiovascular and other tissues. Int J Immunopathol Pharmacol 22: 311-322, 2009.

53. Gao L, Dong Q, Song Z, Shen F, Shi J and Li Y: NLRP3 inflammasome: A promising target in ischemic stroke. Inflamm Res 66: $17-24,2017$

54. Gustin A, Kirchmeyer M, Koncina E, Felten P, Losciuto S, Heurtaux T, Tardivel A, Heuschling P and Dostert C: NLRP3 inflammasome is expressed and functional in mouse brain microglia but not in astrocytes. PLoS One 10: e0130624, 2015.

55. Abais JM, Xia M, Zhang Y, Boini KM and Li PL: Redox regulation of NLRP3 inflammasomes: ROS as trigger or effector? Antioxid Redox Signal 22: 1111-1129, 2015.

56. Sun HS and Feng ZP: Neuroprotective role of ATP-sensitive potassium channels in cerebral ischemia. Acta Pharmacol Sin 34: 24-32, 2013. 
57. He J, Gao Y, Wu G, Lei X, Zhang Y, Pan W and Yu H: Bioinformatics analysis of microarray data to reveal the pathogenesis of brain ischemia. Mol Med Rep 18: 333-341, 2018.

58. Li P, Stetler RA, Leak RK, Shi Y, Li Y, Yu W, Bennett MVL and Chen J: Oxidative stress and DNA damage after cerebral ischemia: Potential therapeutic targets to preserve the genome and improve stroke recovery. Neuropharmacology 134: 208-217, 2018.

59. Buendia I, Tenti G, Michalska P, Méndez-López I, Luengo E, Satriani M, Padín-Nogueira F, López MG, Ramos MT, García AG, et al: ITH14001, a CGP37157-nimodipine hybrid designed to regulate calcium homeostasis and oxidative stress, exerts neuroprotection in cerebral ischemia. ACS Chem Neurosci 8: 67-81, 2017.

60. Burm SM, Zuiderwijk-Sick EA, 't Jong AE, van der Putten C, Veth J, Kondova I and Bajramovic JJ: Inflammasome-induced IL-1 $\beta$ secretion in microglia is characterized by delayed kinetics and is only partially dependent on inflammatory caspases. J Neurosci 35: 678-687, 2015

61. Frank MG, Weber MD, Watkins LR and Maier SF: Stress sounds the alarmin: The role of the danger-associated molecular pattern HMGB1 in stress-induced neuroinflammatory priming. Brain Behav Immun 48: 1-7, 2015.

62. Lee HM, Kang J, Lee SJ and Jo EK: Microglial activation of the NLRP3 inflammasome by the priming signals derived from macrophages infected with mycobacteria. Glia 61: 441-452, 2013.

63. Nagyőszi P, Nyúl-Tóth Á, Fazakas C, Wilhelm I, Kozma M, Molnár J, Haskó J and Krizbai IA: Regulation of NOD-like receptors and inflammasome activation in cerebral endothelial cells. J Neurochem 135: 551-564, 2015.

64. Bauernfeind F, Bartok E, Rieger A, Franchi L, Núñez G and Hornung V: Cutting edge: Reactive oxygen species inhibitors block priming, but not activation, of the NLRP3 inflammasome. J Immunol 187: 613-617, 2011

65. He Q, You H, Li XM, Liu TH, Wang P and Wang BE: HMGB1 promotes the synthesis of pro-IL-1 $\beta$ and pro-IL-18 by activation of $\mathrm{p} 38$ MAPK and NF- $\kappa$ B through receptors for advanced glycation end-products in macrophages. Asian Pac J Cancer Prev 13: 1365-1370, 2012.

66. Liu HD, Li W, Chen ZR, Hu YC, Zhang DD, Shen W, Zhou ML, Zhu L and Hang CH: Expression of the NLRP3 inflammasome in cerebral cortex after traumatic brain injury in a rat model. Neurochem Res 38: 2072-2083, 2013.

67. Muñoz-Planillo R, Kuffa P, Martínez-Colón G, Smith BL, Rajendiran TM and Núñez G: $\mathrm{K}^{+}$efflux is the common trigger of NLRP3 inflammasome activation by bacterial toxins and particulate matter. Immunity 38: 1142-1153, 2013.

68. Adinolfi E, Giuliani AL, De Marchi E, Pegoraro A, Orioli E and Di Virgilio F: The P2X7 receptor: A main player in inflammation. Biochem Pharmacol 151: 234-244, 2018

69. Pétrilli V, Papin S, Dostert C, Mayor A, Martinon F and Tschopp J: Activation of the NALP3 inflammasome is triggered by low intracellular potassium concentration. Cell Death Differ 14: 1583-1589, 2007.

70. Peng TI and Jou MJ: Oxidative stress caused by mitochondrial calcium overload. Ann NY Acad Sci 1201: 183-188, 2010.

71. Heid ME, Keyel PA, Kamga C, Shiva S, Watkins SC and Salter RD: Mitochondrial reactive oxygen species induces NLRP3-dependent lysosomal damage and inflammasome activation. J Immunol 191: 5230-5238, 2013.

72. Sorbara MT and Girardin SE: Mitochondrial ROS fuel the inflammasome. Cell Res 21: 558-560, 2011.

73. Zhou R, Yazdi AS, Menu P and Tschopp J: A role for mitochondria in NLRP3 inflammasome activation. Nature 469: 221-225, 2011.

74. Nakahira K, Haspel JA, Rathinam VA, Lee SJ, Dolinay T, Lam HC, Englert JA, Rabinovitch M, Cernadas M, Kim HP, et al: Autophagy proteins regulate innate immune responses by inhibiting the release of mitochondrial DNA mediated by the NALP3 inflammasome. Nat Immunol 12: 222-230, 2011

75. Yin Y,Zhou Z, Liu W, Chang Q, Sun G and Dai Y: Vascular endothelial cells senescence is associated with NOD-like receptor family pyrin domain-containing 3 (NLRP3) inflammasome activation via reactive oxygen species (ROS)/thioredoxin-interacting protein (TXNIP) pathway. Int J Biochem Cell Biol 84 22-34, 2017

76. Ye X, Zuo D, Yu L, Zhang L, Tang J, Cui C, Bao L, Zan K, Zhang Z, Yang X, et al: ROS/TXNIP pathway contributes to thrombin induced NLRP3 inflammasome activation and cell apoptosis in microglia. Biochem Biophys Res Commun 485: 499-505, 2017.
77. Yang SJ, Shao GF, Chen JL and Gong J: The NLRP3 inflammasome: An important driver of neuroinflammation in hemorrhagic stroke. Cell Mol Neurobiol 38: 595-603, 2018.

78. Wang W, Wang C, Ding XQ, Pan Y, Gu TT, Wang MX, Liu YL, Wang FM, Wang SJ and Kong LD: Quercetin and allopurinol reduce liver thioredoxin-interacting protein to alleviate inflammation and lipid accumulation in diabetic rats. $\mathrm{Br} \mathrm{J}$ Pharmacol 169: 1352-1371, 2013.

79. El-Azab MF, Baldowski BR, Mysona BA, Shanab AY, Mohamed IN, Abdelsaid MA, Matragoon S, Bollinger KE, Saul A and El-Remessy AB: Deletion of thioredoxin-interacting protein preserves retinal neuronal function by preventing inflammation and vascular injury. Br J Pharmacol 171: 1299-1313, 2014

80. Mohamed IN, Hafez SS, Fairaq A, Ergul A, Imig JD and El-Remessy AB: Thioredoxin-interacting protein is required for endothelial NLRP3 inflammasome activation and cell death in a rat model of high-fat diet. Diabetologia 57: 413-423, 2014.

81. Ip WE and Medzhitov R: Macrophages monitor tissue osmolarity and induce inflammatory response through NLRP3 and NLRC4 inflammasome activation. Nat Commun 6: 6931, 2015.

82. West AP and Shadel GS: Mitochondrial DNA in innate immune responses and inflammatory pathology. Nat Rev Immunol 17: 363-375, 2017.

83. Gurung P, Lukens JR and Kanneganti TD: Mitochondria: Diversity in the regulation of the NLRP3 inflammasome. Trends Mol Med 21: 193-201, 2015.

84. Bogdan C: Nitric oxide synthase in innate and adaptive immunity: An update. Trends Immunol 36: 161-178, 2015.

85. Man SM and Kanneganti TD: Regulation of inflammasome activation. Immunol Rev 265: 6-21, 2015.

86. Brough D, Le Feuvre RA, Wheeler RD, Solovyova N, Hilfiker S, Rothwell $\mathrm{NJ}$ and Verkhratsky A: $\mathrm{Ca}^{2+}$ stores and $\mathrm{Ca}^{2+}$ entry differentially contribute to the release of IL-1 $\beta$ and IL- $1 \alpha$ from murine macrophages. J Immunol 170: 3029-3036, 2003.

87. Murakami T, Ockinger J, Yu J, Byles V, McColl A, Hofer AM and Horng T: Critical role for calcium mobilization in activation of the NLRP3 inflammasome. Proc Natl Acad Sci USA 109: 11282-11287, 2012.

88. Horng T: Calcium signaling and mitochondrial destabilization in the triggering of the NLRP3 inflammasome. Trends Immunol 35: 253-261, 2014.

89. Clapham DE: Calcium signaling. Cell 131: 1047-1058, 2007.

90. Humeau J, Bravo-San Pedro JM, Vitale I, Nuñez L, Villalobos C, Kroemer G and Senovilla L: Calcium signaling and cell cycle: Progression or death. Cell Calcium 70: 315, 2018

91. Lee GS, Subramanian N, Kim AI, Aksentijevich I, GoldbachMansky R, Sacks DB, Germain RN, Kastner DL and Chae JJ: The calcium-sensing receptor regulates the NLRP3 inflammasome through $\mathrm{Ca}^{2+}$ and cAMP. Nature 492: 123-127, 2012.

92.Szabadkai G, Bianchi K, Várnai P, De Stefani D, Wieckowski MR, Cavagna D, Nagy AI, Balla T and Rizzuto R: Chaperone-mediated coupling of endoplasmic reticulum and mitochondrial Ca ${ }^{2+}$ channels. J Cell Biol 175: 901-911, 2006.

93. Rizzuto R, Brini M, Murgia M and Pozzan T: Microdomains with high $\mathrm{Ca}^{2+}$ close to IP3-sensitive channels that are sensed by neighboring mitochondria. Science 262: 744-747, 1993.

94. Duchen MR: Mitochondria and calcium: From cell signalling to cell death. J Physiol 529: 57-68, 2000.

95. Eisenbarth SC, Colegio OR, O'Connor W, Sutterwala FS and Flavell RA: Crucial role for the Nalp3 inflammasome in the immunostimulatory properties of aluminium adjuvants. Nature 453: 1122-1126, 2008.

96. Deng D, Jiang N, Hao SJ, Sun H and Zhang GJ: Loss of membrane cholesterol influences lysosomal permeability to potassium ions and protons. Biochim Biophys Acta 1788: 470-476, 2009.

97. Compan V, Baroja-Mazo A, López-Castejón G, Gomez AI, Martínez CM, Angosto D, Montero MT, Herranz AS, Bazán E, Reimers D, et al: Cell volume regulation modulates NLRP3 inflammasome activation. Immunity 37: 487-500, 2012.

98. Okada M, Matsuzawa A, Yoshimura A and Ichijo H: The lysosome rupture-activated TAK1-JNK pathway regulates NLRP3 inflammasome activation. J Biol Chem 289: 32926-32936, 2014.

99. Yaron JR, Gangaraju S, Rao MY, Kong X, Zhang L, Su F, Tian Y, Glenn HL and Meldrum DR: $\mathrm{K}^{+}$regulates $\mathrm{Ca}^{2+}$ to drive inflammasome signaling: Dynamic visualization of ion flux in live cells. Cell Death Dis 6: e1954, 2015.

100. Fann DY, Lim YA, Cheng YL, Lok KZ, Chunduri P, Baik SH, Drummond GR, Dheen ST, Sobey CG, Jo DG, et al: Evidence that NF- $\kappa \mathrm{B}$ and MAPK signaling promotes NLRP inflammasome activation in neurons following ischemic stroke. Mol Neurobiol 55: 1082-1096, 2018. 
101. Jian Z, Ding S, Deng H, Wang J, Yi W, Wang L, Zhu S, Gu L and Xiong X: Probenecid protects against oxygen-glucose deprivation injury in primary astrocytes by regulating inflammasome activity. Brain Res 1643: 123-129, 2016.

102. Ye X, Shen T, Hu J, Zhang L, Zhang Y, Bao L, Cui C, Jin G, Zan K, Zhang Z, et al: Purinergic $2 X 7$ receptor/NLRP3 pathway triggers neuronal apoptosis after ischemic stroke in the mouse. Exp Neurol 292: 46-55, 2017.

103. Murthy P, Durco F, Miller-Ocuin JL, Takedai T, Shankar S, Liang X, Liu X, Cui X, Sachdev U, Rath D, et al: The NLRP3 inflammasome and bruton's tyrosine kinase in platelets co-regulate platelet activation, aggregation, and in vitro thrombus formation. Biochem Biophys Res Commun 483: 230-236, 2017.

104. Peng J, Deng X, Huang W, Yu JH, Wang JX, Wang JP, Yang SB, Liu X, Wang L, Zhang Y, et al: Irisin protects against neuronal injury induced by oxygen-glucose deprivation in part depends on the inhibition of ROS-NLRP3 inflammatory signaling pathway. Mol Immunol 91: 185-194, 2017.

105. Ismael $\mathrm{S}$, Zhao $\mathrm{L}$, Nasoohi $\mathrm{S}$ and Ishrat $\mathrm{T}$ : Inhibition of the NLRP3-inflammasome as a potential approach for neuroprotection after stroke. Sci Rep 8: 5971, 2018.

106. He Q, Li Z, Wang Y, Hou Y, Li L and Zhao J: Resveratrol alleviates cerebral ischemia/reperfusion injury in rats by inhibiting NLRP3 inflammasome activation through Sirtl-dependent autophagy induction. Int Immunopharmacol 50: 208-215, 2017.

107. He YB, Nan LH, Huang M, Zheng YF, Yang L, Xu W and Chu KD: Paeoniflorin down-regulates the expression of NLRP1 and NLRP3 inflammasomes in rat hippocampal slices after oxygen-glucose deprivation. Int J Clin Exp Med 9: 10907-10914, 2016.

108. Qiu J, Wang M, Zhang J, Cai Q, Lu D, Li Y, Dong Y, Zhao T and Chen $\mathrm{H}$ : The neuroprotection of Sinomenine against ischemic stroke in mice by suppressing NLRP3 inflammasome via AMPK signaling. Int Immunopharmacol 40: 492-500, 2016.

109. Rabuffetti M, Sciorati C, Tarozzo G, Clementi E, Manfredi AA and Beltramo M: Inhibition of caspase-1-like activity by Ac-Tyr-Val-Ala-Asp-chloromethyl ketone induces long-lasting neuroprotection in cerebral ischemia through apoptosis reduction and decrease of proinflammatory cytokines. J Neurosci 20: 4398-4404, 2000

110. Ross J, Brough D, Gibson RM, Loddick SA and Rothwell NJ: A selective, non-peptide caspase-1 inhibitor, VRT-018858, markedly reduces brain damage induced by transient ischemia in the rat. Neuropharmacology 53: 638-642, 2007.

111. Lu Y, Xiao G and Luo W: Minocycline suppresses NLRP3 inflammasome activation in experimental ischemic stroke. Neuroimmunomodulation 23: 230-238, 2016.

112. Fann DY, Santro T, Manzanero S, Widiapradja A, Cheng YL, Lee SY, Chunduri P, Jo DG, Stranahan AM, Mattson MP and Arumugam TV: Intermittent fasting attenuates inflammasome activity in ischemic stroke. Exp Neurol 257: 114-119, 2014.

113. Lamkanfi M, Mueller JL, Vitari AC, Misaghi S, Fedorova A, Deshayes K, Lee WP, Hoffman HM and Dixit VM: Glyburide inhibits the Cryopyrin/Nalp3 inflammasome. J Cell Boil 187: $61-70,2009$.

114. Jiang H, He H, Chen Y, Huang W, Cheng J, Ye J, Wang A Tao J, Wang C, Liu Q, et al: Identification of a selective and direct NLRP3 inhibitor to treat inflammatory disorders. J Exp Med 214: 3219-3238, 2017.

115. Primiano MJ, Lefker BA, Bowman MR, Bree AG, Hubeau C, Bonin PD, Mangan M, Dower K, Monks BG, Cushing L, et al: Efficacy and pharmacology of the NLRP3 inflammasome inhibitor CP-456,773 (CRID3) in murine models of dermal and pulmonary inflammation. J Immunol 197: 2421-2433, 2016.

116. Coll RC, Robertson A, Butler M, Cooper M and O'Neill LA: The cytokine release inhibitory drug CRID3 targets ASC oligomerisation in the NLRP3 and AIM2 inflammasomes. PLoS One 6: e29539, 2011

117. Feng X, Luo Q, Wang H, Zhang H and Chen F: MicroRNA-22 suppresses cell proliferation, migration and invasion in oral squamous cell carcinoma by targeting NLRP3. J Cell Physiol 233: 6705-6713, 2018.
118. Byeon HE, Jeon JY, Kim HJ, Kim DJ, Lee KW, Kang Y and Han SJ: MicroRNA-132 negatively regulates palmitate-induced NLRP3 inflammasome activation through FOXO3 down-regulation in THP-1 cells. Nutrients 9: E1370, 2017.

119. Hu H, Wang Y, Ding X, He Y, Lu Z, Wu P, Tian L, Yuan H, Liu D, Shi G, et al: Long non-coding RNA XLOC_000647 suppresses progression of pancreatic cancer and decreases epithelial-mesenchymal transition-induced cell invasion by down-regulating NLRP3. Mol Cancer 17: 18, 2018.

120. Qin YY, Li M, Feng X, Wang J, Cao L, Shen XK, Chen J, Sun M, Sheng R, Han F and Qin ZH: Combined NADPH and the NOX inhibitor apocynin provides greater anti-inflammatory and neuroprotective effects in a mouse model of stroke. Free Radic Biol Med 104: 333-345, 2017.

121. Zhao AP, Dong YF, Liu W, Gu J and Sun XL: Nicorandil inhibits inflammasome activation and toll-like receptor-4 signal transduction to protect against oxygen-glucose deprivation-induced inflammation in BV-2 cells. CNS Neurosci Ther 20: 147-153, 2014.

122. Li C, Wang J, Fang Y, Liu Y, Chen T, Sun H, Zhou XF and Liao H: Nafamostat mesilate improves function recovery after stroke by inhibiting neuroinflammation in rats. Brain Behav Immun 56: 230-245, 2016.

123. Cao G, Jiang N, Hu Y, Zhang Y, Wang G, Yin M, Ma X, Zhou K, Qi J, Yu B, et al: Ruscogenin attenuates cerebral ischemia-induced blood-brain barrier dysfunction by suppressing TXNIP/NLRP3 inflammasome activation and the MAPK pathway. Int J Mol Sci 17: E1418, 2016.

124. Wang X, Li R, Wang X, Fu Q and Ma S: Umbelliferone ameliorates cerebral ischemia-reperfusion injury via upregulating the PPAR gamma expression and suppressing TXNIP/NLRP3 inflammasome. Neurosci Lett 600: 182-187, 2015.

125. Li Y, Li J, Li S, Wang X, Liu B, Fu Q and Ma S: Curcumin attenuates glutamate neurotoxicity in the hippocampus by suppression of ER stress-associated TXNIP/NLRP3 inflammasome activation in a manner dependent on AMPK. Toxicol Appl Pharmacol 286: 53-63, 2015.

126. Zhang N, Zhang X, Liu X, Wang H, Xue J, Yu J, Kang N and Wang X: Chrysophanol inhibits NALP3 inflammasome activation and ameliorates cerebral ischemia/reperfusion in mice. Mediators Inflamm 2014: 370530, 2014.

127. Thakkar R, Wang R, Sareddy G, Wang J, Thiruvaiyaru D, Vadlamudi R, Zhang Q and Brann D: NLRP3 inflammasome activation in the brain after global cerebral ischemia and regulation by 17 $\beta$-estradiol. Oxid Med Cell Longev 2016: 8309031, 2016.

128. Lammerding L, Slowik A, Johann S, Beyer C and Zendedel A: Poststroke inflammasome expression and regulation in the peri-infarct area by gonadal steroids after transient focal ischemia in the rat brain. Neuroendocrinology 103: 460-475, 2016.

129. Zhang S, Jiang L, Che F, Lu Y, Xie Z and Wang H: Arctigenin attenuates ischemic stroke via SIRT1-dependent inhibition of NLRP3 inflammasome. Biochem Biophys Res Commun 493: 821-826, 2017.

130. Yu C, He Q, Zheng J, Li LY, Hou YH and Song FZ: Sulforaphane improves outcomes and slows cerebral ischemic/reperfusion injury via inhibition of NLRP3 inflammasome activation in rats. Int Immunopharmacol 45: 74-78, 2017.

131. Li M, Li H, Fang F, Deng X and Ma S: Astragaloside IV attenuates cognitive impairments induced by transient cerebral ischemia and reperfusion in mice via anti-inflammatory mechanisms. Neurosci Lett 639: 114-119, 2017.

132. Ishrat T, Mohamed IN, Pillai B, Soliman S, Fouda AY, Ergul A, El-Remessy AB and Fagan SC: Thioredoxin-interacting protein: A novel target for neuroprotection in experimental thromboembolic stroke in mice. Mol Neurobiol 51: 766-778, 2015. 